\title{
ESTÁGIO DE DOCÊNCIA NO CURSO DE GRADUAÇÃO EM LETRAS: RE- FLEXÕES SOBRE A LINGUÍSTICA APLICADA CONTEMPORÂNEA E A PRÁTICA PEDAGÓGICA NAS AULA DE LÍNGUA PORTUGUESA
}

\author{
Valéria Castro Nunes* \\ Leticia Fonseca Richthofen de Freitas*
}

\begin{abstract}
RESUMO: Este artigo propõe a reflexão sobre a complexidade da docência e a importância, para a construção de uma identidade docente, de experiências que oportunizem a prática e articule conhecimentos disciplinares com conhecimentos pedagógicos. Sobretudo, o presente trabalho analisa e reflete sobre a da linguagem como constitutiva de significados, evidenciada nas mais recentes abordagens da Linguística Aplicada contemporânea. Além disto, ao discorrer sobre o estágio de docência realizado na disciplina de Linguística Aplicada ao Ensino de Língua Portuguesa, reflete sobre possíveis abordagens para o ensino de língua portuguesa em suas unidades básicas: oralidade, leitura, produção textual e análise linguística, explorando o trabalho com gêneros discursivos.
\end{abstract}

PALAVRAS-CHAVE: Docência; graduação em Letras; linguagem; Linguística Aplicada; ensino de língua portuguesa.

\section{Introdução}

O presente trabalho pretende discorrer, de forma analítica e reflexiva, sobre o estágio de docência que realizei como bolsista do Programa Integrado de Bolsas - mestrado/doutorado (PIB-M/D) da Pró-Reitora de Pesquisa, Pós-Graduação e Inovação (PRPPGI) da Universidade Federal de Pelotas (UFPel). Tal experiência se deu no período de 24 de abril a 26 de junho de 2019, na disciplina de Linguística Aplicada ao Ensino de Língua Portuguesa, que integra a matriz curricular do curso de graduação em Letras da

\footnotetext{
* Mestranda em Letras pela Universidade Federal de Pelotas (UFPel).

** Doutora em Educação pela Universidade Federal do Rio Grande do Sul (UFRS). Realizou estágio de PósDoutorado em Educação na UFRS e em Linguística Aplicada na Universidade Federal do Rio de Janeiro (UFRJ). Professora associada do Centro de Letras e Comunicação e do programa de Pós-Graduação em Letras da Universidade Federal de Pelotas (UFPel) e pesquisadora do Núcleo de Estudos Sobre Currículo Cultura e Sociedade do Programa de Pós-Graduação em Educação da UFRGS.
} 
referida universidade. Este trabalho foi realizado de forma conjunta, tendo a minha participação como estagiária e a participação da Profa. Dra. Letícia Fonseca Richthofen de Freitas como responsável pela disciplina de graduação, na qual ocorreu o estágio, e como minha orientadora no Mestrado, bem como, no estágio em questão.

Conforme o regimento vigente do Programa de Pós-graduação em Letras (2018) da Universidade Federal de Pelotas (UFPel), em sua sessão V, artigo 53, o estágio de docência configura-se em "uma atividade curricular para estudantes de Pós-Graduação stricto sensu definida como a participação em atividades de ensino de Letras na educação superior da UFPel e objetiva a preparação para a docência e a qualificação do ensino de graduação". $\mathrm{Na}$ sequência do documento, em seu parágrafo $1^{\circ}$, estão dispostas as atividades de ensino nas quais o(a) estagiário(a) irá intervir no decorrer do estágio - sendo elas: "I) ministrar aulas teóricas e/ou práticas; II) participar em avaliação parcial de conteúdos programáticos, teóricos e práticos e II) aplicar métodos ou técnicas pedagógicas, como estudo dirigido, seminários etc.

É importante observar que dentre as atividades nas quais o(a) estagiário(a) deverá intervir, trazidas pelo regimento do programa, estão presentes métodos e técnicas pedagógicas. Entende-se, por tanto, que, além de se preocupar em ter o conhecimento dos conteúdos específicos que trabalhará com a turma, o(a) estagiário(a) precisa, ainda, buscar conhecimentos pedagógicos, os quais incluem saberes como: entender como se dá o processo de aquisição da aprendizagem, considerando questões gerais que o envolvem e questões mais particulares, no que se trata, por exemplo, das diferentes maneiras pelas quais diferentes pessoas chegam ao aprendizado; considerar o contexto no qual se dá o desenvolvimento das aulas; estar ciente dos elementos envolvidos no processo de ensino-aprendizagem, nos quais se incluem a integralidade dos estudantes como seres sociais e individuais, a motivação dos mesmos para o aprendizado, os sentidos instituídos em relação aos temas propostos etc. e articular conhecimentos teóricos específicos com aspectos metodológicos e técnicas de ensino, elaborando atividades que possam, de fato, proporcionar o aprendizado. Colocar-se diante de uma turma e fazer um discurso, mesmo que excelente, a respeito de 
um determinado conteúdo, não significa proporcionar a aprendizagem sobre o assunto abordado.

O estágio em questão trata-se da experiência docente de pós-graduandos em turmas de graduação, no entanto, o exercício da docência em geral, da educação infantil ao ensino superior, exige o domínio de conhecimentos teóricos-disciplinares e de conhecimentos pedagógicos, por tanto, estes dois saberes devem, impreterivelmente, estar presente nos cursos de formação de professores. O tema que discute a necessidade de articulação e integração de conhecimentos teóricos específicos e conhecimentos pedagógicos é recorrente em pesquisas sobre o ensino em nível superior, especialmente sobre as licenciaturas (GATTI; NUNES, 2009; LIBÂNEO, 2013), muitos destes estudos evidenciam a pouca atenção dada ao conhecimento e à formação didático-pedagógica - relegada a um papel secundário, em detrimento da formação disciplinar. Libâneo (2015) refere-se ao que ele considera "um dos nós na formação profissional de professores: as dificuldades dos professores em incorporar e articular em seu exercício profissional dois requisitos dessa profissão: o domínio dos conteúdos da disciplina e o domínio de saberes e habilidades para ensinar esses conteúdos (LIBÂNEO, 2015, p. 2).

O referido autor coloca, ainda, que a conduta profissional de professores é influenciada por concepções de formação que creem que uma coisa é o conhecimento disciplinar, com sua estrutura etc. e outra coisa é o conhecimento pedagógico, "entendido como domínio de procedimentos e recursos de ensino sem vínculo com o conteúdo e os métodos de investigação da disciplina ensinada” (LIBÂNEO, 2015, p. 3). É justamente esta crença que deve ser desfeita - é preciso transgredir a ideia dualista que faz com que em cursos de graduação, responsáveis pela formação de futuros docentes, exista a eminente separação entre formação disciplinar e formação pedagógica, sendo a última deixada apenas a cargo da(s) disciplina(s) de didática, geralmente com carga-horária mínima. Reconhecendo o caráter indissociável do conhecimento disciplinar e pedagógico, torna-se evidente a necessidade de que ambos se desenvolvam sincronicamente e possam ser abordados de forma regular nos cursos de licenciatura, adequando-se às características de cada disciplina. 
um sistema de formação de professores precisa buscar uma unidade no processo formativo que assegure relações teóricas e práticas mais sólidas entre a didática e a epistemologia das ciências, rompendo com a separação e o paralelismo entre conhecimentos disciplinares e conhecimentos pedagógico-didáticos. (LIBÂNEO, 2015, p. 19)

Desta forma, no decorrer do estágio realizado na disciplina de Linguística Aplicada ao Ensino de Língua Portuguesa, houve a constante preocupação em articular os conhecimentos teóricos-disciplinares com os conhecimentos didático-pedagógicos, no intuito de contribuir com a formação dos futuros professores e professoras de Língua Portuguesa. No intuito de auxiliar na promoção do aprendizado dos estudantes, foi seguida a proposta da disciplina em questão, que tinha como objetivos aprimorar o conhecimento de diversas abordagens teóricas no âmbito da Linguística Aplicada; refletir sobre a linguagem como constitutiva de significado; considerar diferentes perspectivas a partir das quais a abordagem do ensino de língua materna pode ser desenvolvida; ampliar saberes sobre o letramento e sua relevância em meio às práticas sociais; estudar as unidades básicas do ensino de português: oralidade, leitura, produção textual e análise linguística, explorando variadas possibilidades de trabalhar com gêneros discursivos; ponderar criticamente sobre o papel do professor de Língua Portuguesa na contemporaneidade, bem como sobre as contribuições da Linguística para a formação docente. Buscamos, também, compreender como graduandos do curso Letras assimilam os conhecimentos da Linguística Aplicada em seu percurso, desde aproximadamente 1940, até a LA transgressiva (MOITA-LOPES, 2006) proposta nos dias de hoje. E, ainda em relação aos discentes, procuramos identificar e observar características relevantes na formação de suas performances identitárias enquanto futuros professores de Língua Portuguesa. Além disso, foi possível refletir sobre minha ação enquanto docente em um curso de graduação e sobre a importância do estágio de docência.

\section{Contexto e Metodologia}

A disciplina de Linguística Aplicada ao Ensino de Língua Portuguesa foi oferecida no primeiro semestre letivo de 2019, com aulas semanais que se davam no período das $15 \mathrm{~h} 15 \mathrm{~min}$ às $18 \mathrm{~h} 50 \mathrm{~min}$. A turma contava com 38 alunos matriculados no terceiro semestre 
da graduação, em sua grande maioria nos cursos de Licenciatura em Letras Espanhol/Português e Respectivas Literaturas e Licenciatura em Letras Alemão/Português e Respectivas Literaturas.

Seguindo passos metodológicos que se aproximam da pesquisa-ação, foi feito planejamento, monitoramento e ajustes, com ponderações contínuas e em constante diálogo com os discentes. A elaboração das aulas a serem realizadas no período de estágio se deu com base no plano de ensino da disciplina, desenvolvido pela Profa. Dra. Letícia Fonseca Richthofen de Freitas, que acompanhou e orientou o planejamento das aulas também nesse período.

Em cada encontro, sempre partindo da leitura de textos que tratam de abordagens recentes sobre a Linguística Aplicada e o ensino de língua materna, foram desenvolvidos estudos dirigidos e debates, promovendo a reflexão que veio a servir de base para que elaborassem atividades com as quais fosse possível transpor, para as salas de aula dos ensinos fundamental e/ou médio, propostas para trabalhar oralidade, leitura, escrita e prática de análise linguística. Além disto, foi exercitada pelos discentes a prática da oralidade, que se deu através da apresentação de oratórias - adequando-se à situação comunicativa em questão, ou seja, utilizando-se de vocabulário, de elementos prosódicos, de expressões corporais etc. de forma adequada, bem como, respeitando o tempo estipulado previamente e fazendo uma abordagem apropriada do tema escolhido por eles, os estudantes realizaram oratórias a cada início de aula.

\section{Desenvolvimento}

O primeiro momento das aulas, no qual se davam as oratórias, contava com a presença da professora Letícia, sendo esta primeira atividade desenvolvida juntamente com ela. Cada encontro teve início com as oratórias de aproximadamente seis estudantes que, de forma individual, em um tempo estipulado entre cinco e dez minutos, apresentavam o que já haviam preparado previamente. Logo, era aberto um pequeno espaço de tempo para perguntas e comentários dos colegas. 
Em seguida, a turma, organizada em grupos, discutia questões relativas ao texto selecionado para a aula. A fim de fomentar a reflexão sobre o tema abordado, a partir de cada texto foi proposto um estudo dirigido que norteava as discussões nos grupos - logo, tais discussões eram compartilhadas com a turma em geral. Em meio à atividade, os temas em estudo eram contextualizados e problematizados, sempre com o intuito de mobilizar os estudantes à participação ativa, de maneira que pudessem articular informações e conhecimentos prévios com os estudos promovidos em aula. Dessa forma, evidenciou-se que o diálogo e o debate em sala de aula proporcionam espaço para questionamentos, críticas, discussões e reflexões, colaborando, assim, para a ampliação e diversificação de saberes e configurando-se em ações essenciais para a formação da identidade docente.

Não nos tornamos professores da noite para o dia. Ao contrário, fomos constituindo essa identificação com a profissão docente no decorrer da vida, tanto pelos exemplos positivos, como pela negação de modelos. É nessa longa estrada que vamos constituindo maneiras de ser e estar no magistério. (LIMA, 2012, p. 39)

Ter a consciência de que as performances que assumimos como docentes vão se constituindo ao longo de estudos, pesquisas, práticas, diálogos etc., bem como, saber que, por mais que já tenhamos percorrido esse caminho, tal constituição nunca estará acabada e nunca tomará uma forma rígida, que não permita transformações, reforça a necessidade de serem promovidas, especialmente em cursos de formação docente, ações que fomentem a problematização e a reflexão sobre o papel de professoras e professores, ações que contemplem novas nuances e novas possibilidades, visto que, os saberes se renovam, se somam, se transformam e ganham outros alcances.

A formação pode estimular o desenvolvimento profissional dos professores, no quadro de autonomia contextualizada da profissão docente. Importa valorizar paradigmas de formação que promovam a preparação de professores reflexivos, que assumam a responsabilidade do seu próprio desenvolvimento profissional e que participem como protagonistas na implementação de políticas educativas. (NÓVOA, 1995, p. 27) 
Seguindo tais desdobramentos e pensando o ensino-aprendizagem como um processo que se dá em espiral, foi feito esse movimento nas aulas de Linguística Aplicada ao Ensino de Língua Portuguesa; assim, ideias e relações trazidas por estudos já feitos continuaram a atravessar as discussões promovidas na disciplina no decorrer do semestre letivo. Uma dessas ideias, indispensável para o exercício da profissão docente, em especial para professoras e professores de Língua Portuguesa, é a noção que se tem a respeito do papel da linguagem. Para abordar o tema e ampliar conhecimentos que envolvem tal questão, partimos em um percurso de estudos que possibilitassem o entendimento de como se formam e se transformam ideias, noções, pensamentos, pesquisas etc., buscando sempre associar tais acontecimentos com a Linguística Aplicada.

A turma havia realizado estudos introdutórios sobre diferentes momentos da referida área. Dessa forma, os acadêmicos já tinham conhecimento de fatos como, por exemplo, que a Linguística Aplicada, resultando dos avanços da Linguística como ciência, teve início em meados do século XX e, primeiramente, era entendida apenas como aplicação desta nova ciência, com vistas para a descrição de línguas e o ensino do Inglês. Dando continuidade a tais especulações, perpassamos pelo ponto em que, também na Linguística Aplicada, se abrem caminhos para estudos híbridos, que se comunicam com outras áreas do conhecimento, ou seja, caminhos para a interdisciplinaridade, o que ocorre a partir dos anos de 1970, após duras críticas à vertente aplicacionista. Na mesma época, as pesquisas em LA se voltam para contextos de ensino e aprendizagem de língua materna (MOITA LOPES, 2009) e, nesse percurso, chega, após a chamada "virada linguística", ao que Moita Lopes nomeia Linguística Aplicada Indisciplinar, descrevendo-a como "um modo de criar inteligibilidade sobre problemas sociais em que a linguagem tem um papel central" (MOITA LOPES, 2006, p. 14).

Ao compreender a linguagem como constitutiva da vida institucional, a LA passa a ser formulada como uma área centrada na resolução de problemas da prática de uso da linguagem dentro e fora da sala de aula, ou seja, "a preocupação [é] com problemas de uso da linguagem situados na práxis humana”. (MOITA LOPES, 1996, p. 3) 
Nesse ponto, enfatiza-se a questão crucial sobre o papel da linguagem, que tomou um novo rumo após o que se convencionou chamar de virada linguística. É a partir desse movimento que se passa a "compreender a linguagem como constitutiva da vida institucional" (MOITA LOPES, 1996, p. 3) - sendo este um entendimento indispensável para futuros(as) professores(as) de Língua Portuguesa. Essa nova visão, que teve seu ponto de partida na filosofia analítica e promoveu uma reviravolta nos campos das ciências humanas e sociais em geral, aponta para o fato de que a linguagem não apenas descreve as coisas do mundo, mas atribui a elas significados.

[...] entende-se que, embora os objetos existam no mundo independente da linguagem que usamos para descrevê-los, identificá-los e classificá-los, eles só possuem significado, só passam a existir para nós no momento em que haja uma linguagem para lhe dar sentido. Isso significa que, só ao nomearmos, em uma dada língua, determinados objetos e seres, determinadas qualidades e determinadas ações, é que passamos a "entender" e "perceber" estes objetos e seres, estes atributos, estas ações e acontecimentos - e não outros. O significado, portanto, não surge dos objetos em si, mas sim da linguagem, dos sistemas de classificação nos quais as coisas estão inseridas e que eles conferem significado. (FREITAS, 2013, p. 70 e 71)

Estes sistemas formados na e pela linguagem são sistemas de significação, dos quais os seres humanos se utilizam "para definir o que significam as coisas e para codificar, organizar e regular sua conduta uns em relação aos outros. [...] Tomados em seu conjunto, eles constituem nossas "culturas"' (HALL, 1997, p. 16). Assim, podemos entender que toda a ação social, praticada por meio da linguagem, sendo esta produtora de sentidos, é também uma ação cultural. Tais colocações e citações são trazidas a esse texto para que, mesmo de forma muito breve, sem discorrer mais detalhadamente sobre a virada linguística, tampouco sobre outras tantas viradas que surgiram a partir dela, se possa ter uma ideia geral da amplitude proporcionada pela noção da linguagem constitutiva de significados.

Ao abordarmos a instituição de sentidos como resultado de ações discursivas que se dão em determinado cenário sociocultural e histórico, foi possível explorar também questões relacionadas ao letramento, tema há pouco estudado pela turma. Signorini (2001) 
propõe, com base em seus estudos, que as práticas de letramento sejam compreendidas como "o conjunto de ações e atividades orientadas para a interação social, que envolvem o uso da leitura e da escrita e que integram a dinâmica da vida cotidiana dos indivíduos e dos grupos de uma dada comunidade" (SIGNORINI, 2001, p. 114). A autora refere-se ao caráter sócio-histórico e à dimensão processual de toda atividade de uso da escrita que, dentre as práticas de comunicação social, é compreendida como:

modo de intervenção na/pela linguagem, numa dada conjuntura sociocultural e histórica, e, portanto, numa dada dinâmica multifacetada e complexa, envolvendo objetivos, recursos e instrumentos variados - não só os de natureza propriamente tecno-formal, como o código e as tipologias textuais, por exemplo. E não se trata apenas de uma intervenção num "contexto" pré-existente, mas de uma forma de ação que tanto é constituída e moldada pela conjuntura sociocultural e histórica e pela dinâmica das relações sociais quanto constitui e molda essa conjuntura e essa dinâmica. (SIGNORINI, 2001, p. 115)

Como vemos, as práticas de letramento não se dissociam dos sistemas de significação estabelecidos discursivamente. Reforça-se aqui a necessidade de se discutir tais conceitos em cursos de formação docente, pois estes conhecimentos devem alicerçar outros tantos estudos, entre eles, os estudos sobre as unidades básicas do ensino de língua portuguesa: oralidade, leitura, produção textual e análise linguística. Freitas (2013, p. 75) sublinha a "importância de se desenvolver a competência discursiva - e ela envolve a competência linguística - de nossos alunos e alunas". Há de se pensar, a partir da colocação de Freitas, em um ponto chave - quem, nas salas de aula dos ensinos fundamental e médio, será responsável por promover o desenvolvimento da competência discursiva e linguística dos alunos e alunas? A primeira resposta que nos vem à mente é de que serão esses 38 estudantes matriculados na disciplina de Linguística Aplicada ao Ensino de Língua Portuguesa; mas, na verdade, serão eles e todos os futuros professores e professoras de Língua Portuguesa, para os quais ficará verdadeiramente difícil, se não impossível, desenvolver tais habilidades em seus discentes, se eles próprios não as tiverem desenvolvidas de forma consistente e segura. Daí a grande importância de se promover espaços nos cursos de graduação em 
Letras, para que os estudantes ampliem conhecimentos e aprimorem suas próprias habilidades linguísticas e discursivas, pois grande parte deles chegam à universidade ainda em nível incipiente em determinadas competências essenciais.

No decorrer das aulas buscou-se sempre otimizar o entendimento a respeito das características discursivas e linguísticas a serem observadas na leitura, na escrita e na oralidade. Estas características nos levam à materialidade da língua em seu caráter discursivo e apontam para os sistemas de significação, que estão embutidos nos mais diferentes textos (orais e escritos). Desenvolver competências discursivas, analisando caraterísticas importantes em textos orais e/ou escritos, nos permite uma visão mais sensível e perspicaz, que nos leva a perceber com maior nitidez como e com que propósito se formam redes discursivas. Desta forma, fica claro que "mais do que um instrumento de comunicação, a língua é um fator chave nessa luta para a imposição de significados sociais" (FREITAS, 2013, p. 75). Cabe ressaltar a sugestão feita pela autora, na sequência de seu texto:

[...] há que se pensar o ensino de língua como um campo de produção de significados e a sala de aula como local onde se produzem, se discutem e se negociam significados. Além disso, os próprios processos de negociação e de imposição de significados podem ser trazidos para sala de aula e nela serem discutidos, a fim de que os alunos percebam que a língua é um palco de lutas e de tensões e não apenas a concretização de regras gramaticais. (FREITAS, 2013, p. 75)

As palavras de Freitas (2013) correspondem à direção tomada nas aulas de Linguística Aplicada ao Ensino de Língua Portuguesa, as quais contaram sempre com iniciativas que levassem os futuros professores e professoras ali presentes a entender a língua (e as aulas de língua que ministrarão futuramente) em seu sentido mais amplo, não apenas como "instrumento de comunicação" e/ou "concretização de regras gramaticais". Seguindo esse caminho, os estudos na disciplina em questão voltaram-se aos gêneros discursivos, conforme o pensamento bakhtiniano, "pelo qual toda produção linguística deve ser entendida como uma forma de ação social, situada sócio historicamente” (LOPES-ROSSI, 2006, s/p). 
Dessa forma, passa-se a refletir sobre o "conjunto integrado de atividades de leitura e produção de textos orais e escritos", que constituem a "matéria" de Língua Portuguesa (SIMÕES, 2008).

Todas as esferas da atividade humana, por mais variadas que sejam, estão sempre relacionadas com a utilização da língua. [...] A utilização da língua efetua-se em forma de enunciados (orais e escritos) [...] cada esfera de utilização da língua elabora seus tipos relativamente estáveis de enunciados, sendo isso que denominamos gêneros do discurso. (BAKHTIN, 1997, p. 290)

Como coloca Bakhtin (2003), todas as esferas da atividade humana estão relacionadas com a utilização da língua e elaboram seus enunciados relativamente estáveis, o autor parte desta constatação para organizar seu pensamento sobre gêneros discursivos. Sabendo disto, podemos perceber que o trabalho com gêneros discursivos se configura em um vasto e fértil terreno a ser explorado pelo professor de Língua Portuguesa, possibilitando o exercício da oralidade, da leitura, da produção textual e da análise linguística. O docente, partindo de estudos individuais e da ampliação de seus próprios conhecimentos, deve elaborar projetos pedagógicos que explorem todas as propriedades do gênero discursivo a ser trabalhado (LOPES-ROSSI, 2006).

Ainda segundo LOPES-ROSSI (2006, s/p), "no estudo de um gênero, além das características discursivas, devem ser observadas a organização composicional, a organização do texto verbal, aspectos linguísticos e de estilo e marcas enunciativas mais típicas." Assim sendo, faz-se necessário que as futuras professoras e os futuros professores de Língua Portuguesa estejam conscientes da importância do planejamento, que "demanda tempo e uma variedade de habilidades" (BUTT, 2009, p. 16). Desenvolver um projeto que trabalhe um determinado gênero discursivo em todas as suas propriedades, de forma a oferecer às alunas e aos alunos maiores possibilidades de se apropriarem do conhecimento da maneira mais ampla e eficaz possível, exige que professoras e professores, além do que já foi colocado, sejam sensíveis ao propor atividades que ampliem os saberes mas que, ao mesmo tempo, estejam dentro da realidade e das possibilidades da turma e do ambiente ao qual estão inseridos. Assim, é preciso ter uma visão bastante ampla, que permita um planejamento com recursos viáveis dentro do contexto, com tarefas muito bem definidas, para 
que sejam desenvolvidas em tempo adequado, sendo concluídas todas as etapas necessárias para que, de fato, seja promovido o aprendizado. Dessa forma, ao priorizar o aprendizado, a preocupação primeira dos professores e professoras não deve ser na quantidade de gêneros trabalhados e sim no planejamento de atividades sequenciais e diversas, que deem conta de explorar todas as propriedades de um gênero discursivo, o que se dará em várias aulas, podendo estender-se bimestral ou trimestralmente. O diálogo sobre a essencialidade do planejamento, e dos ajustes muitas vezes necessários, aconteceu em diversos momentos das aulas de Linguística Aplicada ao Ensino de Língua Portuguesa - questões como as colocadas neste parágrafo foram discutidas em meio aos estudos de abordagens teóricas.

[...] o educador, conhecendo a teoria que sustenta a sua prática, pode suscitar transformações na conscientização dos educandos e demais colegas, chegando até aos condicionantes sociais, tornando o processo ensino aprendizagem em algo realmente significativo, em prol de uma educação transformadora, que supere os déficits educacionais atuais. (GASPARIN, PENETUCC, 2008, p. 3)

As colocações feitas por Gasparin e Penetucc (2008) destacam a importância de o educador ter sempre uma teoria que sustente sua prática. Segundo os autores, o conhecimento da teoria, atrelado à prática, possibilitará ações docentes de fato transformadoras. Em conformidade com este pensamento e com o intuito de proporcionar aos discentes a oportunidade de pensar a prática de forma consoante com as discussões teóricas promovidas em aula, foi proposto o desenvolvimento de um exercício de elaboração de atividade. Tomando por base o estudo do texto de Lopes-Rossi (2006), que sugere procedimentos para o estudo de um gênero discursivo, bem como todos os estudos teóricos realizados até então, os estudantes, nos últimos momentos de cada aula, elaboraram atividades pensadas para trabalhar oralidade, leitura e escrita com turmas dos anos finais do ensino fundamental e/ou com turmas de ensino médio.

Já organizados em seis grupos, os graduandos passaram à elaboração de tais atividades - discutiram, em seus respectivos grupos, sobre que atividade iriam propor e com quais objetivos, considerando as habilidades a serem desenvolvidas em suas alunas e seus 
alunos. Para isto, definiram o gênero discursivo (oral ou escrito) a partir do qual trabalhariam e o suporte de texto a ser utilizado; definiram, também, quais recursos seriam necessários e quais seriam os procedimentos metodológicos, ou seja, de que forma a atividade seria aplicada - quais seriam os passos para o desenvolvimento da mesma. Logo, cada grupo apresentava a atividade elaborada aos demais colegas e à professora.

\section{Algumas ponderações}

Cabe aqui retomarmos alguns pontos sobre a Linguística Aplicada contemporânea. Moita Lopes (2006), ao trazer a ideia de indisciplina, propõe o rompimento das fronteiras disciplinares, o desprendimento, o abandono de dogmas positivistas, historicamente viciados, que insistem em negar a hibridez que inevitavelmente se evidencia no mundo; com isto, o autor sugere o diálogo entre diferente áreas do conhecimento e a exploração de novos caminhos, para que se possa somar epistemologicamente e ampliar conhecimentos sobre a linguagem e seu uso na práxis humana (MOITA LOPES, 2009). Pennycook (2006, p. 74-75) nos fala em "produzir outros modos de pensar", enquanto Fabrício (2006, p. 48) nos faz refletir sobre o fato de que "se a linguagem é uma prática social, ao estudarmos a linguagem estamos estudando a sociedade e a cultura das quais ela é parte constituinte e constitutiva" - obviamente, os autores referem-se aos rumos da LA em relação à pesquisa e à interdisciplinaridade. No entanto, como docentes em uma sala de aula de um curso de formação de futuros professores e professoras de Língua Portuguesa, seguindo passos de uma Linguística Aplicada Indisciplinar e incentivando esses futuros profissionais a serem professores(as) pesquisadores(as), a terem um olhar reflexivo, crítico e transgressor sobre a própria prática, nada mais coerente do que nossas ações irem ao encontro de tais propósitos - também na sala de aula, de modo geral, devemos "produzir outros modos de pensar", devemos nos perguntar como estamos olhando para a diversidade, a mestiçagem, a hibridez de corpos e mentes de nossos(as) alunos(as). Certamente somos passíveis de erros, o que reforça a importância de estarmos sempre vigilantes com nossos próprios atos incluindo nossa prática docente. 
Como foi colocado desde o início, esse trabalho foi desenvolvido conjuntamente, no entanto, como experiencio de forma inaugural a docência no ensino superior, obviamente, minha orientadora, sem deixar de cumprir seu papel, permitiu que eu tivesse autonomia e espaço suficientes para, de fato, vivenciar essa docência da forma mais integral possível, tendo, assim, a possibilidade de intervir, observar, analisar e refletir sobre essa nova experiência. Minha prática docente até o momento se deu nos ensinos fundamental e médio. Então, ao pensar em um plano de estudo, a ser desenvolvido em um estágio de graduação, pensei (idealizei), por se tratar de uma turma de universitários(as), em discentes com plena maturidade para a assunção de uma autonomia responsiva do aprendizado e da construção do próprio conhecimento. Entretanto, depois dos primeiros encontros com a turma mudei meu pensamento e precisei rever atitudes relativas à minha intervenção no processo de ensino-aprendizagem desses alunos e alunas. Meu discurso sempre foi em prol de que cada grupo, e cada indivíduo que o compõe, possui suas idiossincrasias, é único e precisa ser observado, conhecido e considerado pela(o) docente, mesmo assim, muito provavelmente por encontrar-me envolvida em um sistema de significação que estabelece, de forma geral e uniforme, uma performance para o sujeito universitário - como pessoa adulta, que escolheu estar ali, por tanto está pronta para ser gestora do próprio aprendizado, atribuí à turma, antecipadamente, características que não se concretizaram.

Estivemos durante esse período com um grupo extremamente rico, composto por discentes com grande potencial, o que os fez avançar muito em seu processo de aprendizagem. No entanto, o grupo era composto, em sua maioria, por alunas e alunos muito jovens ou por quem havia parado de estudar por muitos anos e precisava se reorganizar nessa caminhada; tal realidade exigiu certos ajustes e atitudes docentes mais estritas, a fim de auxiliá-los, também, na assunção de atitudes e estratégias que os levassem ao melhor aproveitamento de suas próprias habilidades; além disto, foi necessário o planejamento de aulas que contemplassem mais amplamente os diferentes modos pelos quais se dá o aprendizado, atendendo os estudantes em necessidades ainda presentes nesse momento de suas caminhadas acadêmicas e, ao mesmo tempo, promovendo o alcance de maior autonomia. 
Em relação aos conteúdos trabalhados, foi possível perceber a incipiência dos discentes na compreensão da linguagem como constitutiva de significados e da Linguística Aplicada como transgressora - o que é compreensível, pois processos que demandam mudanças não ocorrem de um dia para o outro, na verdade estão em constante transformação, a própria palavra processo remete à ação contínua e prolongada, a seguimento, a curso que requer um determinado tempo, no qual as ações realizadas levarão ao movimento objetivado. Portanto, é preciso que tenhamos em mente que a concepção de linguagem fora da visão descritiva, instrumental e denotacionista e a ideia de uma Linguística Aplicada que transcende os limites da Linguística, do ensino de línguas estrangeiras e da tradução ainda é muito recente em termos de ciência. A compreensão da linguagem como constitutiva de significados, como elemento medular na construção do conhecimento e da vida social e a LA como uma área centrada na prática de uso da linguagem dentro e fora da sala de aula (MOITA LOPES, 2009) passa a ser realidade no Brasil somente a partir do final do século XX. Então, é compreensível que os graduandos ainda estejam sendo apresentados a essas concepções. No entanto, compreender que tal processo está em andamento não significa banalizar ações, de forma que isto venha a retardá-lo ou estagná-lo. Tais ideias são essenciais e precisam ser estudadas cada vez mais nos Cursos de Letras e muito bem compreendidas pelos estudantes.

O exercício, realizado pela turma, de elaboração das atividades de prática docente, pensadas com o objetivo de trabalhar oralidade, leitura e escrita, em turmas dos ensinos fundamental e/ou médio, levou à reflexão sobre alguns pontos observados: a) o potencial criativo de muitos(as) dos(as) graduandas(as), demonstrado ao apresentarem ideias explorando novas tecnologias e aproximando-se do que é atual e faz parte da vida da maioria dos adolescentes e jovens, podendo assim, além de desenvolver as habilidades pretendidas, levar os alunos e alunas a uma maior motivação para as aulas, o que, como sabemos, potencializa o aprendizado; b) a tendência a reproduzir atividades convencionalmente propostas nas escolas de modo geral, como: ler um livro e socializar seu conteúdo com a turma ou entregar ao professor(a) uma escrita sobre o mesmo; compor uma canção tendo como tema algum conteúdo gramatical etc. É provável que tais ideias tenham surgido como efeito 
produzido por ações repetidas que sistematizam e determinam modelos, os quais passam a ser vistos não como uma dentre inúmeras opções, mas como a regra a ser seguida. É importante que os futuros professores e professoras de Língua Portuguesa compreendam que atividades como estas não estão erradas ou vetadas, não é uma questão de certo ou errado e sim de desprendimento, de hibridização, de explorar novos caminhos levando na bagagem elementos encontrados em caminhos já percorridos e que devem nos acompanhar, porém, sem que nos impeçam de ir além e alcançar outros espaços e c) o fato de que a observação anterior (ponto b), torna ainda mais evidente a necessidade de ações consistentes, a serem desenvolvidas nos cursos de Letras, que levem à compreensão da língua/linguagem em toda sua complexidade. A língua não se reduz a sua gramática ou a canônicas interpretações de textos, ou seja, a elementos apresentados à parte, como se fossem de outro domínio; a língua está presente no grupo familiar, na comunidade, na sala de aula e, em sua utilização, produz efeitos de sentidos. Este conhecimento configura-se como base para que os futuros docentes reconheçam a possibilidade de trilhar novos caminhos.

\section{Palavras Finais}

Esses dois meses de estágio de docência, o que parece um espaço de tempo tão pequeno - e na verdade o é, foram, porém, grandes no que se refere à riqueza da experiência. Cada vivência é única - mesmo tendo mais de uma década de experiência em sala de aula nos ensinos fundamental e médio, minhas descobertas e meu aprendizado no estágio de graduação muito acrescentaram em minha construção enquanto docente, o que evidencia que essa construção é contínua e as performances que assumimos são constantemente remodeladas.

Além do que agrega na experiência docente do(a) pós-graduando(a), o estágio de docência é uma rica oportunidade de troca também para os(as) graduandos(as), que estão construindo identidade docente. Assim sendo, é relevante destacar que os estudos realizados no decorrer da disciplina, discussões teóricas, propostas de prática etc. resultaram em um grande avanço da turma em geral, em relação ao conhecimento adquirido pelo grupo, referente aos temas propostos. Cabe destacar ainda, os momentos reservados 
às trocas/relatos de experiências que se deram no decorrer das aulas, especialmente por parte de alguns alunos e alunas que já exercem a profissão docente e por minha parte, ao compartilhar com a turma experiencias que tive enquanto professora de Língua Portuguesa nos ensinos fundamental e médio - pude perceber que esse diálogo, além de motivar os estudantes, oportunizou questionamentos, discussões e pensamento crítico em relação à prática atrelada a teoria e, fundamentalmente, os aproximou da prática docente real e humana, pois dividi com a turma experiências de sucesso, mas também aquelas que não deram tão certo, o que, além de oportunizar a análise do porquê não deu tão certo e o que poderia ter sido feito diferente, os fez perceber que nossa construção enquanto docentes não ocorre de forma mágica e perfeita, mas é justamente isso que a enriquece, o mais importante é estarmos sempre atentos e dispostos a aprender.

Por fim, considero importante destacar que a oportunidade de estar em um papel que tanto valorizo, o de docente no processo de formação de professoras e professores, potencializou o valor que atribuo a esses profissionais e me fez perceber com maior clareza o grande comprometimento necessário no desempenho desta função, que demanda aprofundamento teórico contínuo, bem como permanente reflexão sobre a própria prática. Cabe, ainda, enfatizar que experiências como a que é apresentada aqui nos colocam diante de inúmeras situações, relativas ao exercício da docência e ao ensino de línguas, que podem e devem ser problematizadas - o que nos instiga à pesquisa e evidencia o fato de que os temas a serem abordados não se esgotam e a produção científica sobre os mesmos é extremamente necessária para embasar a formação docente.

\section{ETAPA DE ENSEÑANZA EN LETRAS, CURSO DE GRADUACIÓN: REFLEXIONES SOBRE LA LINGÜÍSTICA APLICADA CONTEMPORÁNEA Y LA PRÁCTICA PEDAGÓGICA EN CLASES DE LENGUA PORTUGUESA}

RESUMEN: Este artículo propone una reflexión sobre la complejidad de la docencia y la importancia, para la construcción de una identidad docente, de experiencias que brinden la oportunidad del ejercicio de la enseñanza y que asocie conocimiento disciplinario y conocimiento pedagógico. Sobre todo, el presente trabajo analiza y reflexiona sobre el lenguaje constructora de significados, evidenciado en los enfoques más recientes de la Lingǘstica Aplicada contemporánea. Además, al analizar las prácticas docentes realizadas en la disciplina de Lingüística Aplicada a la enseñanza de la Lengua 
Portuguesa, reflexiona sobre los posibles enfoques para la enseñanza del portugués en sus unidades básicas: oralidad, lectura, producción textual y análisis lingüístico, explorando el trabajo con géneros discursivos.

PALABRAS-CLAVE: Docencia; graduación en Letras; lenguaje; Lingüística Aplicada; enseñanza de lengua portuguesa.

\section{REFERÊNCIAS}

BAKHTIN, M. Os gêneros do discurso. In: BAKHTIN, M. Estética da criação verbal. São Paulo: Martins Fontes, 1997.

ELLIOTT, J. La investigación-acción en educación. 3. ed. Madrid: Morata, 1997.

FABRÍCIO, B. F. Linguística Aplicada como espaço de desaprendizagem: redescrições em curso. In: MOITA LOPES, L. P. (org). Por uma linguística aplicada indisciplinar. São Paulo: Parábola, 2006. P. 45-65.

FREITAS, L. F. R. de. Estudos culturais de ensino de língua portuguesa: articulações e perspectivas. In: PAES, M. H. R.; SILVEIRA, R. M. H. (Org.). Contribuições para o trabalho e formação docente: temas contemporâneos e sala de aula. 1.ed. - Curitiba: CRV, 2013.

GASPARIN, José Luiz; PENETUCCI, Maria Cristina. Pedagogia histórico-crítica: da teoria à prática no contexto escolar. Disponível em http://www.diadiaeducacao.pr.gov.br/portals/pde/arquivos/2289-8.pdf Acesso em: 22 fev. 2020.

GATTI, Bernadete Angelina; NUNES, Muniz Rossa (Org.). Formação de professores para o ensino fundamental: estudo de currículos das licenciaturas em pedagogia, língua portuguesa, matemática e ciências biológicas. São Paulo: Fundação Carlos Chagas/DPE, 2009.

HALL, Stuart. A centralidade da cultura: notas sobre as revoluções do nosso tempo. Educação \& Realidade. Porto alegre: UFRGS, v. 22, n. 02, jul./dez. 1997.

LIBÂNEO, José Carlos. Integração entre Didática e Epistemologia das Disciplinas: uma via para a renovação dos conteúdos da didática. In: DALBEN, Angela et al. (Org.). Convergências e tensões no campo da formação e do trabalbo docente: didática, formação de professores, trabalho docente. Belo Horizonte: Autêntica, 2010a. P. 81-104.

- O ensino da didática, das metodologias específicas e dos conteúdos específicos do ensino fundamental nos currículos dos cursos de pedagogia. Revista Brasileira de Estudos Pedagógicos, Brasília, v. 91, n. 229, p. 562-583, set./dez. 2010 b.

. Formação de professores e didática para desenvolvimento humano. Educação \& Realidade, Porto Alegre: UFRGS, vol. 40, n. 2, abr./jun. 2015. 
LIMA, Maria Socorro Lucena. Estágio e aprendizagem da profissão docente. Brasília: Líder Livro, 2012.

LOPES-ROSSI, M. A. G. Procedimentos para estudo de gêneros discursivos da escrita. Revista Intercâmbio, São Paulo: LAEL/PUC-SP, v. 15, ISSN 1806-275X, 2006.

MOITA LOPES, Luiz Paulo da. Afinal, o que é Linguística Aplicada? In: MOITA LOPES, L.P. Oficina de linguística aplicada. Campinas: Mercado de Letras, 1996. (Org.). Por uma linguística aplicada indisciplinar. São Paulo: Parábola Editorial, 2006. Da aplicação de linguística à linguística aplicada indisciplinar. In: PEREIRA, R. C.; ROCA, P (orgs.). Linguística aplicada: um caminho com muitos acessos. São Paulo: Contexto, 2009.

NÓVOA, Antônio. Formação de professores e profissão docente. In: NÓVOA, Antônio (org.). Os professores e a sua formação. Lisboa: Dom Quixote, 1995.

PENNYCOOK, A. Uma linguística aplicada transgressiva. In: MOITA LOPES, L. P. (org). Por uma linguística aplicada indisciplinar. São Paulo: Parábola, 2006. P. 67-84.

SIGNORINI, I. Construindo com a escrita "outras cenas de fala". In: SIGNORINI, I.(org.) Investigando a relaşão oral/ escrito e as teorias do letramento. Campinas: Mercado de Letras, 2001.

SIMÕES, L. J. Texto e interação na aula de língua materna. In: PEREIRA, Nilton M. et al. Ler e escrever: compromisso no ensino médio. Porto Alegre: Ed. da UFRGS, 2008.

Recebido em: 01/05/2020.

Aprovado em: 25/05/2020. 